\title{
The value of a 1-day multidisciplinary robot surgery training for novice robot surgeons
}

Citation for published version (APA):

Beulens, A. J. W., Brinkman, W. M., Porte, P. J., Meijer, R. P., van Merrienboer, J. J. G., Van der Poel, H. G., \& Wagner, C. (2019). The value of a 1-day multidisciplinary robot surgery training for novice robot surgeons. Journal of Robotic Surgery, 13(3), 435-447. https://doi.org/10.1007/s11701-018-0894-2

Document status and date:

Published: 01/06/2019

DOI:

10.1007/s11701-018-0894-2

Document Version:

Publisher's PDF, also known as Version of record

Document license:

Taverne

Please check the document version of this publication:

- A submitted manuscript is the version of the article upon submission and before peer-review. There can be important differences between the submitted version and the official published version of record.

People interested in the research are advised to contact the author for the final version of the publication, or visit the DOI to the publisher's website.

- The final author version and the galley proof are versions of the publication after peer review.

- The final published version features the final layout of the paper including the volume, issue and page numbers.

Link to publication

\footnotetext{
General rights Owners
rights.

- You may freely distribute the URL identifying the publication in the public portal. please follow below link for the End User Agreement:

www.umlib.nl/taverne-license

Take down policy

If you believe that this document breaches copyright please contact us at:

repository@maastrichtuniversity.nl

providing details and we will investigate your claim.
}

Copyright and moral rights for the publications made accessible in the public portal are retained by the authors and/or other copyright owners and it is a condition of accessing publications that users recognise and abide by the legal requirements associated with these

- Users may download and print one copy of any publication from the public portal for the purpose of private study or research.

- You may not further distribute the material or use it for any profit-making activity or commercial gain

If the publication is distributed under the terms of Article $25 \mathrm{fa}$ of the Dutch Copyright Act, indicated by the "Taverne" license above, 


\title{
The value of a 1-day multidisciplinary robot surgery training for novice robot surgeons
}

\author{
Alexander. J. W. Beulens ${ }^{1,2} \cdot$ Willem M. Brinkman ${ }^{3}$. Petra J. Porte ${ }^{1,7} \cdot$ Richard P. Meijer $^{4}$. \\ Jeroen J. G. van Merriënboer ${ }^{5} \cdot$ Henk G. Van der Poel $^{6} \cdot$ Cordula Wagner $^{1,7}$
}

Received: 21 June 2018 / Accepted: 14 November 2018 / Published online: 22 November 2018

๑) Springer-Verlag London Ltd., part of Springer Nature 2018

\begin{abstract}
Introduction To fulfil the need for a basic level of competence in robotic surgery (Brinkman et al., Surg Endosc Other Interv Tech 31(1):281-287, 2017; Dutch Health inspectorate (Inspectie voor de gezondheidszorg), Insufficient carefulness at the introduction of surgical robots (in Dutch: Onvoldoende zorgvuldigheid bij introductie van operatierobots), Igz, Utrecht, 2010), the NIVEL (Netherlands Institute for Healthcare Research) developed the 'Basic proficiency requirements for the safe use of robotic surgery' (BPR). Based on the BPR a 1-day robotic surgery training was organised to answer the following research questions: (1) Are novice robot surgeons able to accurately self-assess their knowledge and dexterity skills? (2) Is it possible to include the teaching of all BPRs in a 1-day training?

Materials and methods Based on the BPR, a robot surgery course was developed for residents and specialists (surgery, gynaecology and urology). In preparation, the participants completed an online e-module. The 1-day training consisted of a practical part on robot set-up, a theoretical section, and hands-on exercises on virtual reality robot simulators. Multiple online questionnaire was filled out by the participants at the end of the training to evaluate the perceived educational value of the course and to self-assess the degree to which BPRs were reached.

Results 20 participants completed the training during the conference of the Dutch Association for Endoscopic Surgery (NVEC) in 2017. Participants indicated nearly all competency requirements were mastered at the end of the training. The competency requirements not mastered were, however, critical requirements for the safe use of the surgical robot. Skill simulation results show a majority of participants are unable to reach a proficient simulation score in basic skill simulation exercises. Conclusion Results show novice robot surgeons are too positive in the self-assessment of their own dexterity skills after a 1-day training. Self-assessment revealed uncertainty of the obtained knowledge level on requirements for the safe use of the surgical robot. Basic courses on robotic training should inform trainees about their results to enhance learning and inform them of their competence levels.
\end{abstract}

Keywords Training $\cdot$ Robot surgery $\cdot$ Robot simulation $\cdot$ Novice $\cdot$ Skill assessment

Alexander. J. W. Beulens

Alexander.beulens@catharinaziekenhuis.nl

1 Netherlands Institute for Health Services Research (NIVEL), Utrecht, The Netherlands

2 Department of Urology, Catharina Hospital, P.O. Box 1350, 5602 ZA Eindhoven, The Netherlands

3 Department of Urology, Erasmus Medical Centre, Rotterdam, The Netherlands
4 Department of Oncological Urology, University Medical Centre Utrecht, Utrecht, The Netherlands

5 School of Health Professions Education, Maastricht University, Maastricht, The Netherlands

6 Department of Urology, Dutch Cancer Institute-Antoni van Leeuwenhoek Hospital, Amsterdam, The Netherlands

7 Amsterdam Public Health Research Institute, VU Medical Centre, Amsterdam, The Netherlands 


\section{Introduction}

Over the past years, much has changed for robot surgeons. Where the first robot surgeons received a short mandatory training in the basics of robotic surgery by the manufacturer, the next generation of robot surgeons has the possible advantage of a supervisor at their hospital to train them in their specific field of robotic surgery. Not all of these new robot surgeons do have access to the manufacturers basic training program since they are not necessarily new consumers of a robotic system. This could result in a gap in the training of residents and fellows since training of the basics of robotic surgery is currently not routinely implemented in their curricula. In 2010, the Dutch Health Care Inspectorate (IGZ) published a report stating 'insufficient carefulness at the introduction of surgical robots'. In this report, the IGZ expressed its concern regarding robot-assisted laparoscopy. This report stated that in most hospitals, the criteria for novice robot-assisted laparoscopy were either vague or completely lacking $[2,3]$. The lack of structured training, defined skill-criteria, and a systematic training needs analysis results in a personal training programme developed by the novice surgeons based on their own perceived lack of knowledge [4,5]. This could result in a hiatus of knowledge due to overconfidence biases, an over-assessment of their own skill compared to the objective assessment of skill by an external observer [6].

To clarify criteria for starting robot-assisted surgery, the Netherlands Institute for Health Services Research (NIVEL) developed the 'Basic proficiency requirements for the safe use of robotic surgery (BPR) [7]. As it was developed in co-operation with a surgeon, urologist, and a gynaecologist, these requirements transcend each of these individual disciplines and provide a guide to ensure each surgeon using a surgical robot has the required minimum of knowledge and skill to start preforming robot-assisted surgery [7].

In earlier research, we investigated whether the current specialists think a basic training in robot surgery should be developed to guarantee a basic level of skills for all new robot surgeons [1]. The majority of robot professionals in the Netherlands agree that the basics in robotic surgery should be learned in a structured training program to guarantee the quality of the surgeon and the safety of the patient. Since basic robot training could be similar for the different specialties such as general surgery, gynaecology, and urology a multidisciplinary basic robotic skills training could be a feasible and effective training method. To safeguard the quality the programme can be developed using the proficiency criteria defined by the NIVEL [1]. Although several authors have investigated the development of a basic training in robotic surgery, no actual accepted basic robot surgery training has been implemented yet $[8,9]$.
In this study, we aim to answer the following research questions (1) Are novice robot surgeons able to accurately self-assess their knowledge and dexterity skills? (2) Is it possible to include the teaching of all BPRs in a 1-day training? We will answer both questions by evaluating the outcomes of a 1-day multidisciplinary robot surgery training.

\section{Methods}

\section{Participants}

As part of the Dutch Association for Endoscopic Surgery (NVEC) conference of March 2017 in Amsterdam a multidisciplinary robot surgery training was organized. The training was given 1 day before the conference. Specialists and residents from urology, general surgery and gynaecology were invited to participate in the training. A total of 20 participants pre-registered for this training.

\section{Materials}

For this training different types of materials were used to instruct the participants. Prior to the training all participants were invited to complete a specific e-learning module (http://www.davincisurgerycommunity.com), to become more familiar with the Intuitive Surgical da Vinci Xi robotic system.

During the training three types of virtual reality simulators (The MIMIC dV-Trainer, Intuitive surgical da Vinci skills simulator, and the 3D Systems RobotiX Mentor) were used to test the participants' dexterity skills on the robot surgery system. An Intuitive Surgical da Vinci Xi system was used during a hands-on draping and docking training, and an interactive presentation was given by an experienced (robot)-anaesthetist.

During the training multiple questionnaires were filled out by the participant. An online Pre-training questionnaire on demographics and prior robot surgery or robot surgery simulation experience ("Appendix 1"). An online BPR questionnaire based on the BPRs developed by NIVEL (see "Appendix 2"). The questionnaire consisted of 37 questions on the participants self-assessed competence of the basic proficiency requirements. This questionnaire was used to assess if the participants were prone to accurately assess their own dexterity skills compared to the objective assessment of simulator skill (overconfidence bias). The questionnaires were developed by a group of urologists and the overall perceived educational value of the training was examined using a third online questionnaire, the perceived educational value questionnaire (see "Appendix 3"). All questionnaires were validated using face validity by a panel of experts in the field of surgical robotics. 
During the introduction of the training the participants were informed that all data would be analysed anonymously. Informed consent was given by all participants. Under Dutch law no ethical review is necessary for this type of study.

\section{Procedure}

The training consisted of pre-training preparation, a theoretical session, a practical session on the robot set-up and a simulation session on virtual reality simulators (Fig. 2 in "Appendix 4").

\section{Pre-training preparation}

The pre-training preparation consisted of an e-learning module (http://www.davincisurgerycommunity.com), and basic skills training at the participants' own hospital. The e-learning helped participants to become familiar with the specific robot platform and took approximately $2 \mathrm{~h}$ to complete. Since research shows at least $10 \mathrm{~h}$ of basic skills training is needed to become proficient in basic robot surgery skills [10], participants were recommended to do at least $10 \mathrm{~h}$ of basic skills training in their own hospital, on both simulator and dry lab facilities if available.

\section{Training}

Participants commenced the training by filling out an online Pre-training questionnaire ("Appendix 1").

The first part of the training was a hands-on training using the Intuitive Surgical da Vinci Xi system taking $80 \mathrm{~min}$. During this part of the training draping and docking and patient positioning were explained with demonstrations and hands-on training. It covered requirements of the 'BPR' about 'robot functionalities', 'image' and 'preparation' [7].

The second part of the training consisted of an interactive presentation was given taking $30 \mathrm{~min}$. This presentation dealt with general safety issues and anaesthetic difficulties, addressed by an (robot)-anaesthesiologist. This part of the training covered requirements of the "BPR" [7] about 'communication', 'emergency situations', 'power supply', and 'preparation'.

The third part of the training consisted of Simulation sessions were organized to test the participants skill in robotassisted procedures and to test requirements of the 'BPR' about console functionality [7] taking $70 \mathrm{~min}$. During this simulation session, multiple exercises were performed. Participants were instructed to do their best at these exercises, they were aware this was not an opportunity for training. To include all essential robotic skills, exercises were selected based on four categories of essential robotic skills (Camera navigation and clutch control, wrist manipulation, needle driving, and suturing) identified at the fundamentals of robotic surgery (FRS) consortium meetings [8]. The following exercises were performed by the participants:

- On the MIMIC dV-Trainer:

- Pick and Place exercise (Fig. 1a), this exercise simulates the ability to move the arms of the robot.

- Camera Targeting I exercise (Fig. 1b), this exercise simulates the ability to move the arms and camera of the robot.

- Pick and Place clutching exercise (Fig. 1c), this exercise simulates the ability to move the arms and camera of the robot.

- On the Intuitive surgical da Vinci skills simulator

- Energy and Dissection II exercise (Fig. 1d), this exercise simulates the ability to move the arms, the camera of the robot, and to used coagulation of blood vessels.

- On the 3D Systems RobotiX Mentor

- Suturing exercise (Fig. 1e), this exercise simulates the ability to move the arms and camera of the robot.

All exercises resulted in simulator generated performance scores, which were used to assess the skills of the participant. These scores were based on a multitude of variables, for example, the mastery of the workspace, instrument collisions, economy of motion, and use of excessive force. To determine which of the participants passed the individual exercises the scores of the MIMIC dV-Trainer were analysed by the developer of the simulator [11]. The threshold scores used are the same as the regular thresholds for the simulation exercises on the MIMIC dV-Trainer system. This means participant passed the exercise if their scores were equal or higher than the median score of data collected from more than 100 experienced surgeons with over 75 robotic cases completed [11]. Each simulator and exercise had its own scale of scores and threshold score to indicate proficient comprehension of the exercise. Participants were kept unaware of their results of the skill simulation exercises. No reference scores were provided for participants for the individual skill simulation exercises.

At the end of the training, the participants were asked to complete an online BPR questionnaire ("Appendix 2") and the perceived educational value questionnaire (“Appendix 3").

\section{Data analysis}

Statistical package for the social sciences (SPSS) version 24 was used for the analysis. Non-parametric tests were used to compare the difference in simulation scores from the first and second attempt at the skill simulation exercises to evaluate progress of the participants. Correlations between self-assessment scores and simulation scores were calculated 

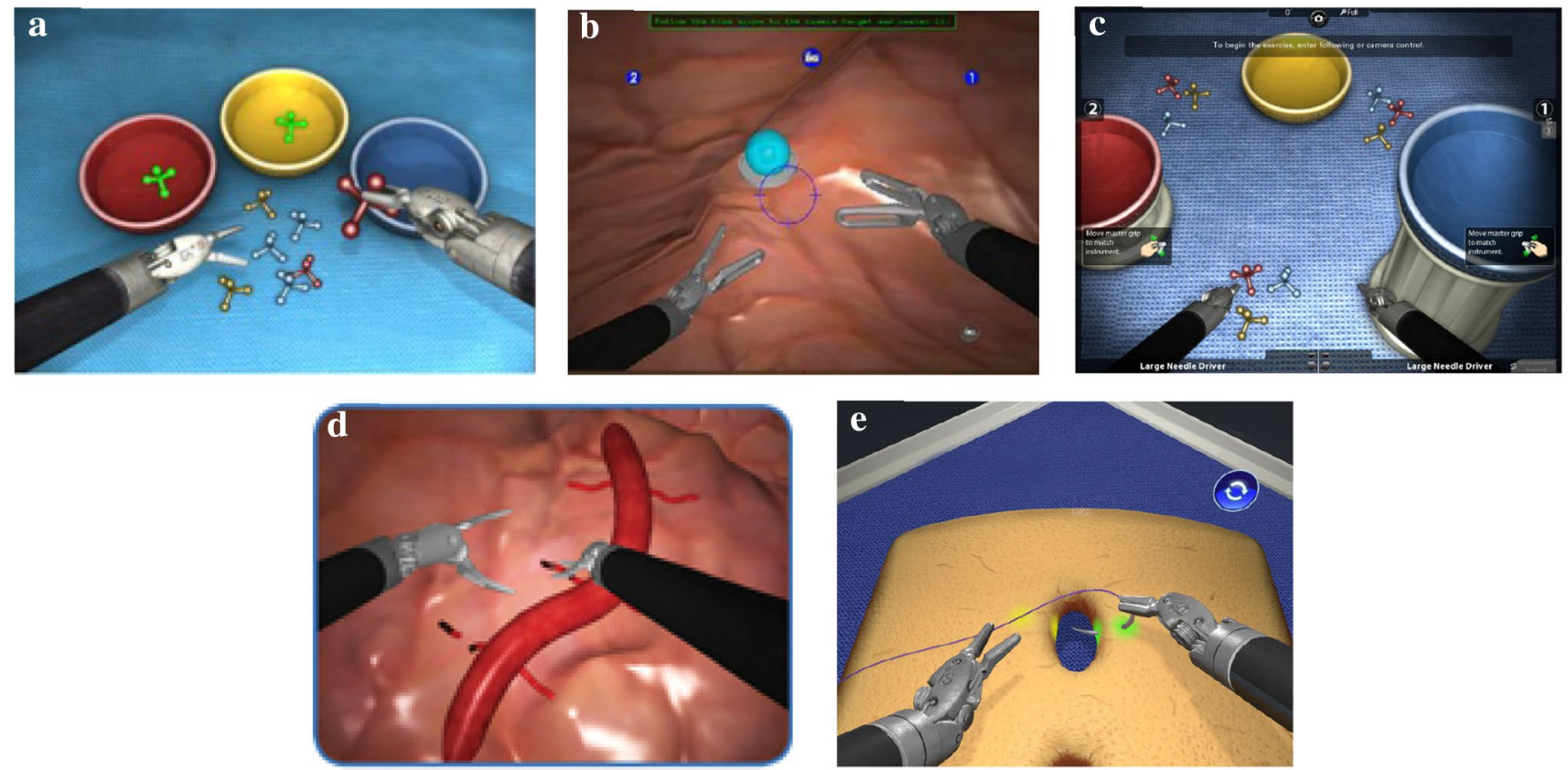

Fig. 1 Examples of the simulation exercises; a pick and place exercise, $\mathbf{b}$ camera targeting I exercise, $\mathbf{c}$ pick and place clutching exercise, $\mathbf{d}$ energy and dissection II exercise, e suturing exercise

using the bivariate correlation tests giving the Pearson correlation. The alpha level was set at 0.05 .

\section{Results}

\section{Participants}

Of the 20 physicians who participated in the multidisciplinary robot surgery training, fourteen completed the demographics questionnaire ("Appendix 1"), the results are shown in Table 1.

All participants completed the hands-on draping and docking exercises and visited the interactive lecture of the robot anaesthesiologist. There was no significant difference in both simulation and real-life robot experience between residents and specialists. Most participants (11/14) did not complete the suggested $10 \mathrm{~h}$ of skill simulator training as preparation of the multidisciplinary robot surgery training.

\section{Simulation test results}

All participants had the opportunity to repeat each exercise once to practice the tasks. The results of both attempts (Table 5 in "Appendix 5") were compared in order to evaluate progress (Table 2).

The Pick and Place exercise (performed on the MIMIC $\mathrm{dV}$-Trainer) provides insight in the participants' ability to move the robot arms. This exercise was performed once
Table 1 Participant characteristics

\begin{tabular}{lc}
\hline Characteristics & Participants $(n=14)$ \\
\hline Occupation & 5 \\
Specialists & 9 \\
Residents & \\
Discipline & 2 \\
Urology & 9 \\
General Surgery & 3 \\
Gynaecology & \\
Robot simulation experience & 11 \\
$<10 \mathrm{~h}$ & 3 \\
$>30 \mathrm{~h}$ & \\
Surgical robot experience & 6 \\
$0 \mathrm{~h}$ & 6 \\
$1-10 \mathrm{~h}$ & 1 \\
$10-20 \mathrm{~h}$ & 1 \\
$>30 \mathrm{~h}$ &
\end{tabular}

as a warm up by all participants. Based on the criteria the developer of the simulator set for the exercise $8(44 \%)$ of the participants obtained a passing score (Table 3 ).

The Pick and Place clutching exercise (performed on the MIMIC dV-Trainer) provides insight into the participants ability to move the arms of the robot. When comparing the scores of the first and second attempt (Table 2), the second attempt showed a significant improvement in the overall 
Table 2 Simulation scores per exercise comparing the median scores of the first and second attempt

\begin{tabular}{llll}
\hline Exercise & \multicolumn{2}{l}{ Attempt, median (min/max) } & \multirow{2}{*}{$p$ value } \\
\cline { 2 - 3 } & 1 & 2 & \\
\hline Pick and place & $619(462-1125)$ & NA & NA \\
Pick and place clutching & $461(183-639)$ & $560(296-688)$ & 0.002 \\
Camera targeting I & $512(219-940)$ & $780(286-939)$ & 0.293 \\
Energy dissection & $38(0-65)$ & $67(22-83)$ & 0.001 \\
Suture exercise & & & \\
Total time to complete & $670(21-1257)$ & $292(24-566)$ & 0.002 \\
Needle drops & $16(0-30)$ & $9(0-20)$ & 0.016 \\
Accurate needle passes & $92(0-100)$ & $95(0-100)$ & 0.449 \\
\hline
\end{tabular}

Table 3 passed results for the MIMIC dV-Trainer simulation exercises

\begin{tabular}{lll}
\hline Exercise & Attempt 1 & Attempt 2 \\
\hline $\begin{array}{l}\text { Pick and place } \\
\text { Pass, } n(\%)\end{array}$ & $8(44)$ & NA \\
$\begin{array}{l}\text { Pick and place clutching } \\
\text { Pass, } n(\%)\end{array}$ & $0(0)$ & $0(0)$ \\
Camera targeting I & & \\
Pass, $n(\%)$ & $9(47)$ & $10(58)$ \\
\hline
\end{tabular}

score $(p=0.002)$. Based on the criteria the developer of the simulator set for the exercise, none of the participants obtained a passing simulation score (Table 3 ).

The Camera Targeting I exercise (performed on the MIMIC dV-Trainer) provides insight into the participant's ability to move the arms of the robot and how the camera is operated. Based on the criteria the developer of the simulator set for the exercise, 9 (47\%) participants obtained a passing score on the first attempt and 10 (58\%) participants obtained a passing score on the second attempt (Table 4). When comparing the scores of the first and second attempt (Table 2) no significant difference in median simulation scores were found.

The Intuitive surgical da Vinci skills simulator was used to perform the Energy and Dissection II exercise. The Energy and Dissection II exercise provides insight into the participants ability to move the arms, the operation and movement of the camera, and the use of monopolar and bipolar coagulation. The comparison (Table 2) showed a significant improvement in the overall score for the second attempt $(p=0.001)$.

The suturing exercise (performed on the 3D Systems RobotiX Mentor) provides insight into the participants ability to move the arms of the robot and the operation and movement of the camera. For this exercise, results from different variables were analysed. These variables
Table 4 correlation between number of mastered requirements and simulation scores

\begin{tabular}{llr}
\hline Exercise & Attempt & \multicolumn{1}{l}{$r(p)$} \\
\hline Pick and place & 1 & $0.35(0.915)$ \\
Pick and place clutching & 1 & $-0.235(0.440)$ \\
Camera targeting I & 2 & $-0.169(0.582)$ \\
Energy dissection & 1 & $-0.315(0.294)$ \\
& 2 & $-0.222(0.512)$ \\
Suture exercise & 1 & $-0.587(0.097)$ \\
Total time to complete & 2 & $-0.285(0.457)$ \\
& 1 & $-0.707(0.033)^{\#}$ \\
Needle drops & 2 & $-0.007(0.988)$ \\
Accurate needle passes & 1 & $-0.456(0.217)$ \\
& 2 & $-0.397(0.330)$ \\
& 2 & $0.085(0.828)$ \\
\hline
\end{tabular}

$r$ Pearson correlation

\#Significant correlation $(p<0.05)$

included the total time to complete the exercise, the number of needle drops during the exercise, and the percentage of accurate needle passes. The total time to complete the exercise showed a significant decrease in the second attempt $(p=0.002)$ (Table 2). The number of needle drops showed a significant decrease of needle drops in the second attempt $(p=0.016)$ (Table 2).

\section{Questionnaire results}

The BPR questionnaire ("Appendix 2") was based on the 'BPR' developed by the NIVEL [7]. The questions investigated the participants self-assessed competence in each of the basic proficiency requirements at the end of the training. The questions can be divided into 7 categories; 'Robot functionalities', 'image', 'preparation', 'console functionalities', 'communication', 'emergency situations', and 'power supply'.

A majority of the participants (71.4\%) reported most requirements ( 32 of the 37 situations) as mastered (Table 5 in "Appendix 5"). The five situations which were reported as not mastered by a large portion of the participants were; how to undo an emergency stop of the robot (not mastered by $75 \%$ of the participants), how to act in case of a power failure (not mastered by $62.5 \%$ of the participants), how to check all the articulating instruments (not mastered by $56.3 \%$ of the participants), the meaning of the different icons on the display (not mastered by $43.8 \%$ of the participants), and how to take into account in advance that the table 
cannot be moved after docking (not mastered by $35.7 \%$ of the participants).

All participants responded they mastered the basic proficiency requirements [7] (console functionality) corresponding to the MIMIC dv-Simulator scores. Whilst MIMIC dvSimulator simulation exercises were performed proficiently by $0 \%, 44 \%$ and $58 \%$ of the participants (in order, Pick and place clutching exercise, Pick and Place exercise, and Camera Targeting exercise).

In almost all exercises the correlation between number of mastered requirements and the simulation scores (Table 4) was lacking. The only significant correlation was found in the first attempt of the suture exercise. The total time to complete the exercise was shorter for participants who reported they mastered more requirements.

The perceived educational value of the multidisciplinary robot surgery training was investigated using the perceived educational value questionnaire in "Appendix 3". The participants graded the training with an 8.19 out of 10 .

\section{Discussion}

In this study, we aimed to answer the following research questions: (1) Are novice robot surgeons able to accurately estimate their knowledge and dexterity skills after initial training? (2) Is it possible to include the basic proficiency requirements for the safe use of robotic surgery as developed by the NIVEL in a 1 day training? To answer these questions, we analysed the results of a 1-day training programme which included BPR.

To answer if novice robot surgeons are able to accurately estimate their theoretical knowledge and dexterity skills the questionnaire results are compared to the results from the MIMIC dv-Simulator simulation exercises. Although the questionnaire results are based on a self-reported competence judgement by the participants, and not the result of a test or simulation exercise, it illustrates participants feel competent to deal with the provided situations at the end of training. However, this feeling might not be completely justified as the results of the MIMIC dv-Simulator simulation exercises were performed proficiently by $0 \%, 44 \%$ and $58 \%$ of the participants. Participants were kept unaware of their skill simulation scores and the corresponding reference scores. Since all participants responded they, in their opinion, mastered the requirements corresponding to these simulation exercises this could be a case of over-assessment of their own skill compared to the objective assessment of this skill (overconfidence biases). This phenomenon has been described in multiple studies [6,12].

Since the questionnaire about the basic proficiency requirements was not filled out until after the training, and no pre-training-measurement was performed it is difficult to say if this self-reported mastery of the basic proficiency requirements can only be attributed to over-assessment of the participants in their skill alone or if the participants mastery of the simulation exercises is not a valid measurement for the mastery of the basic proficiency requirements developed by the NIVEL. Although face validity of the questionnaire was investigated using a panel of expert in the field of robotic surgery further validation of the questionnaire was not possible since no similar questionnaires exist and the response was too small to perform statistical validation of the questionnaire.

Participant's theoretical knowledge was not tested during the training. We assume the results of their self-reported evaluation are influenced by the same principle of overconfidence bias. To investigate if this is the case testing of theoretical knowledge has to be integrated in a further implementation of the training.

To answer if it is possible to include the basic proficiency requirements for the safe use of robotic surgery as developed by the NIVEL in one training the results of the questionnaire and skill simulation results were used.

The questionnaire results, based on a self-reported competence judgement by the participants, show that almost all (32/37) requirements for the safe use of the surgical robot are mastered in the opinion of the participants. It is worrying a large proportion of the participants feel they did not master critical requirements for the safe use of the surgical robot (i.e., how to act in case of a power failure and to undo an emergency stop). Although results are based on a small number of respondents, these situations need to be addressed more in further implementation of the training.

Based on the skill simulation results none of the participants were competent in the MIMIC dV-Trainer basic skill simulation exercises after 1 day of training, which could be the result of the lack of skill simulator experience in most participants. Although all participants were instructed to train at least $10 \mathrm{~h}$ [10], a large portion of participants attended the training without prior simulator experience. Participants do show an improvement in the scores of the second repetition of almost all exercises. This could also be the result of the warming up effect after the first attempt at the exercise. To investigate the origin of this improvement in simulation scores, multiple repetitions of the exercise would be required.

Based on the results presented in this article we are unable to asses if participants were proficient in all BPR after the 1-day training programme. We do believe this training covers all important aspects of system training (containing different modality's of training, i.e., hands-on training combined with theoretical information) as indicated by previous research [14]. Although this training was completed by a small group of participants who did not all provided their demographic data and answers to the questionnaires 
based on the BPR [7], this study gave insights into the further development of a training based on basic proficiency requirements and the use of simulation scores to get more insight in the mastery of the basic proficiency requirements. It remains unclear if, with proper preparation, participants could be proficient in all BPR after the 1-day training programme.

Although all participants did report they mastered the basic proficiency requirements which could be related to the simulation exercises, a majority of participants did not achieve a proficient score in the simulation exercises. To investigate if this discrepancy can be attributed to overconfidence bias or if simulation exercises are a valid measurement for the mastery the BPR [7] further research in larger groups of participants with a more thoroughly validated questionnaire is needed.

Based on our observations we may conclude that objective assessment of knowledge and dexterity skills is mandatory and results should be discussed with the trainees to tailor further training accordingly.

\section{Conclusion}

Results show novice robot surgeons are unable to accurately self-assess their obtained dexterity skills. Since theoretical knowledge was not tested it is impossible to conclude if participants are able to adequately asses their theoretical knowledge of the basic proficiency requirements. Further testing of both theoretical knowledge and dexterity skills is advised in further implementation of the training to asses if it is possible to incorporate all BPR in a 1-day multi-disciplinary robot surgery training.

\section{Compliance with ethical standards}

Conflict of interest Drs. Beulens, Dr. Brinkman, Dr. Meijer, Dr. van Merrienboer, Dr. van der Poel, and Dr. Wagner have no conflicts of interest or financial ties to disclose. Dr. Porte reports grants from the Dutch Ministry of Health, Welfare and Sport, during the conduct of the study.

\section{Appendix 1: Pre-training questionnaire, demographic data}

1. What is your profession?
A. Specialist
B. residents

2. What is your specialism
A. Surgery
C. Gynaecology
D. Urology

3. How much experience do you have with the da Vinci Robot?
A. Assist during surgery and practice on a simulator
B. only assisting during surgery
C. only practice on a simulator
D. surgery on a real patient
E. No experience with the da Vinci Robot

4. How many hours did you practice with the simulator or robot exercises?
A. $<10 \mathrm{~h}$
B. $10-20 \mathrm{~h}$
C. $20-30 \mathrm{~h}$
D. $\mathrm{D}>30 \mathrm{~h}$

5. How many hours did you operate on a real patient with the da Vinci Robot?
A. $0 \mathrm{~h}$
B. $1-10 \mathrm{~h}$
C. $10-20 \mathrm{~h}$
D. $20-30 \mathrm{~h}$
E. $>30 \mathrm{~h}$

\section{Appendix 2: Questionnaire on basic requirements based on the basic proficiency requirements for the safe use of robotic surgery as developed by the NIVEL}

1. Do you know the advantages and limitations of using the surgical robot?
A. Yes
B. No

2. Do you know how the arms are put in position?
A. Yes
B. No

3. Do you know how the trocars can be connected to the arms?
A. Yes
B. No

4. Do you know the possibilities and degrees of freedom of the arms? 

A. Yes
B. No

5. Do you know the functionalities of the tower?
A. Yes
B. No

6. Do you know the functionalities of the robot?
A. Yes
B. No

7. Do you know the functionalities of the console?
A. Yes
B. No

8. Do you know how to solve collisions between the arms of the robot?
A. Yes
B. No

9. Do you know how the control of the surgical arms can be taken over from the console?
A. Yes
B. No

10. Do you know how to act if the instruments do not move/respond properly?
A. Yes
B. No

11. Do you know how the laparoscopic instruments can be inserted correctly under vision?
A. Yes
B. No

12. Do you know why the instruments need to be searched out of vision with the Camera?
A. Yes
B. No

13. Do you know what the various icons on the screen mean?
A. Yes
B. No

14. Do you know how the robot can be safely moved?
A. Yes
B. No

15. Do you know how the robot can be safely connected?
A. Yes
B. No

16. Do you know how all articulating instruments can be checked?
A. Yes
B. No

17. Do you know how the robot is positioned?
A. Yes
B. No

18. Do you know how the robot is docked?
A. Yes
B. No

19. Do you know how instruments can be Placed and exchanged?
A. Yes
B. No

20. Do you know how the number of lives of the instruments can be controlled?
A. Yes
B. No

21. Do you know how you can take into account in advance that the table cannot be moved after docking?
A. Yes
B. No

22. Do you know how to position the patient in a safe way?
A. Yes
B. No

23. Do you know how the patient can be fixed?
A. Yes
B. No 
24. Do you know how the face of patients is protected during the procedure?
A. Yes
B. No

25. Do you know how the console can be adjusted in terms of ergonomics?
A. Yes
B. No

26. Do you know how the Camera is operated from the console?
A. Yes
B. No

27. Do you know how the Camera can be moved and zoomed in and out?
A. Yes
B. No

28. Do you know how the instruments can be moved?
A. Yes
B. No

29. Do you know how between arms can be changed?
A. Yes
B. No

30. Do you know how monopolar and bipolar coagulation can be activated?
A. Yes
B. No

31. Do you know what needs to be discussed with the anaesthesiologist specifically in the area of robot surgery?
A. Yes
B. No

32. Do you know how to give good instructions according to the closed-loop principle (because of the lack of eye contact and the view of the operator on the patient)?
A. Yes
B. No

33. Do you know how to convert in an emergency situation?
A. Yes
B. No

34. Do you know how the robot can be disconnected with the help of an Allen key?
A. Yes
B. No

35. Do you know where the emergency stop of the robot is?
A. Yes
B. No

36. Do you know how pressing the emergency stop can be undone?
A. Yes
B. No

37. Do you know how to deal with power outages?
A. Yes
B. No

\section{Appendix 3: Questionnaire on perceived educational value of the training}

1. If you have to give this training a grade of $1-10$ ? What grade would you give?

2. What could be improved in this training?

\section{Appendix 4}

See Fig. 2. 
Fig. 2 Program flow diagram

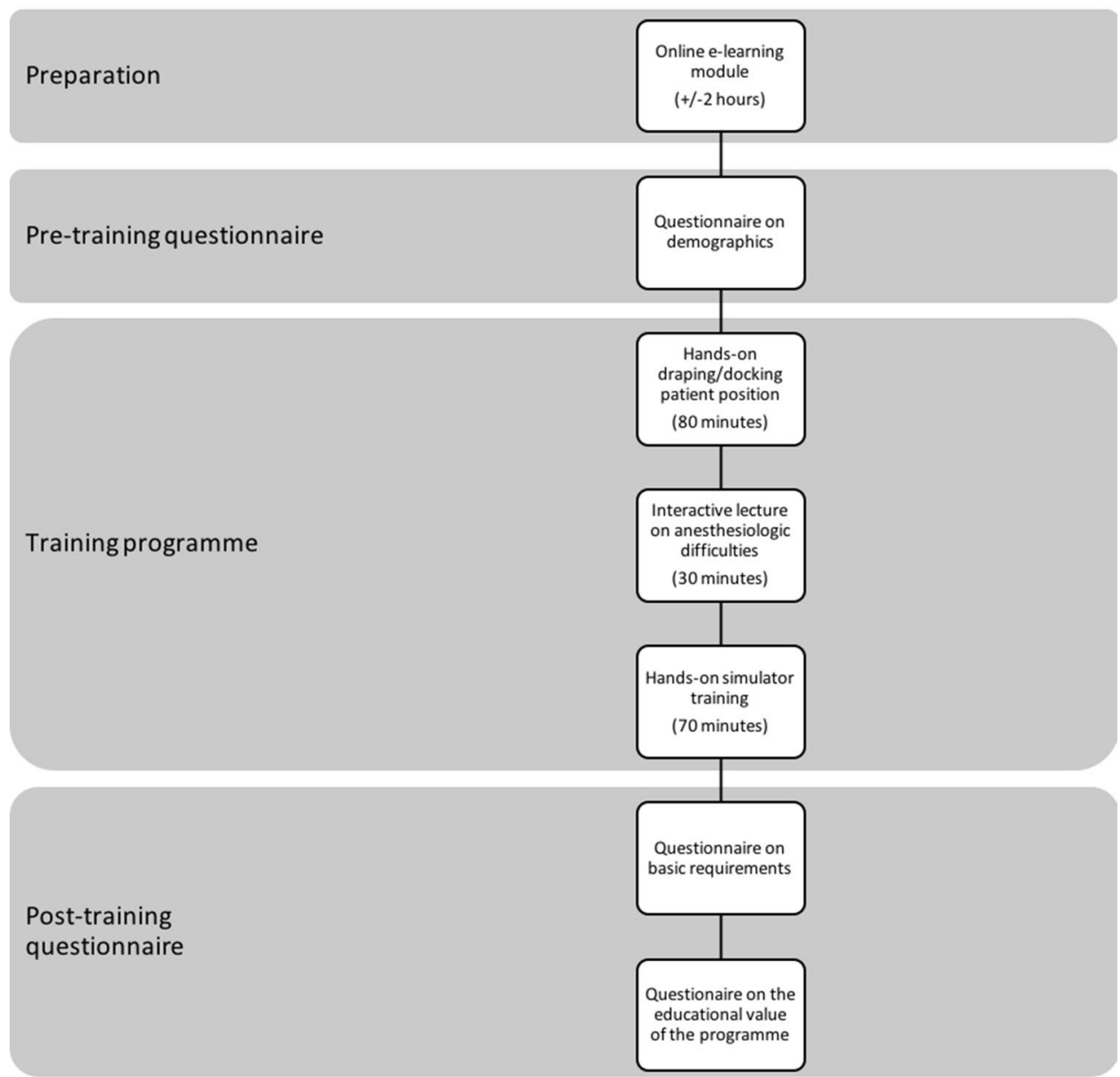

\section{Appendix 5}

See Table 5. 


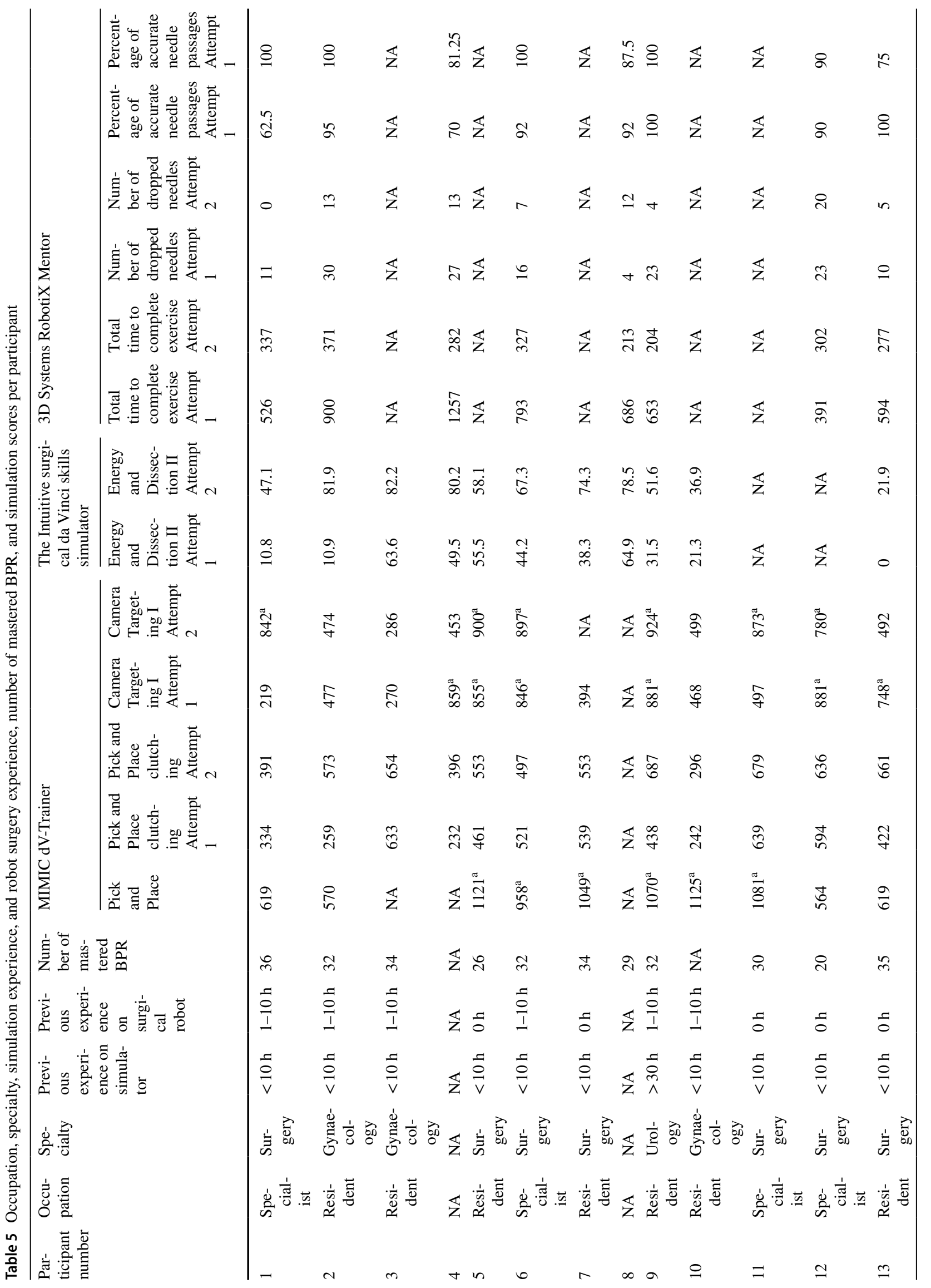




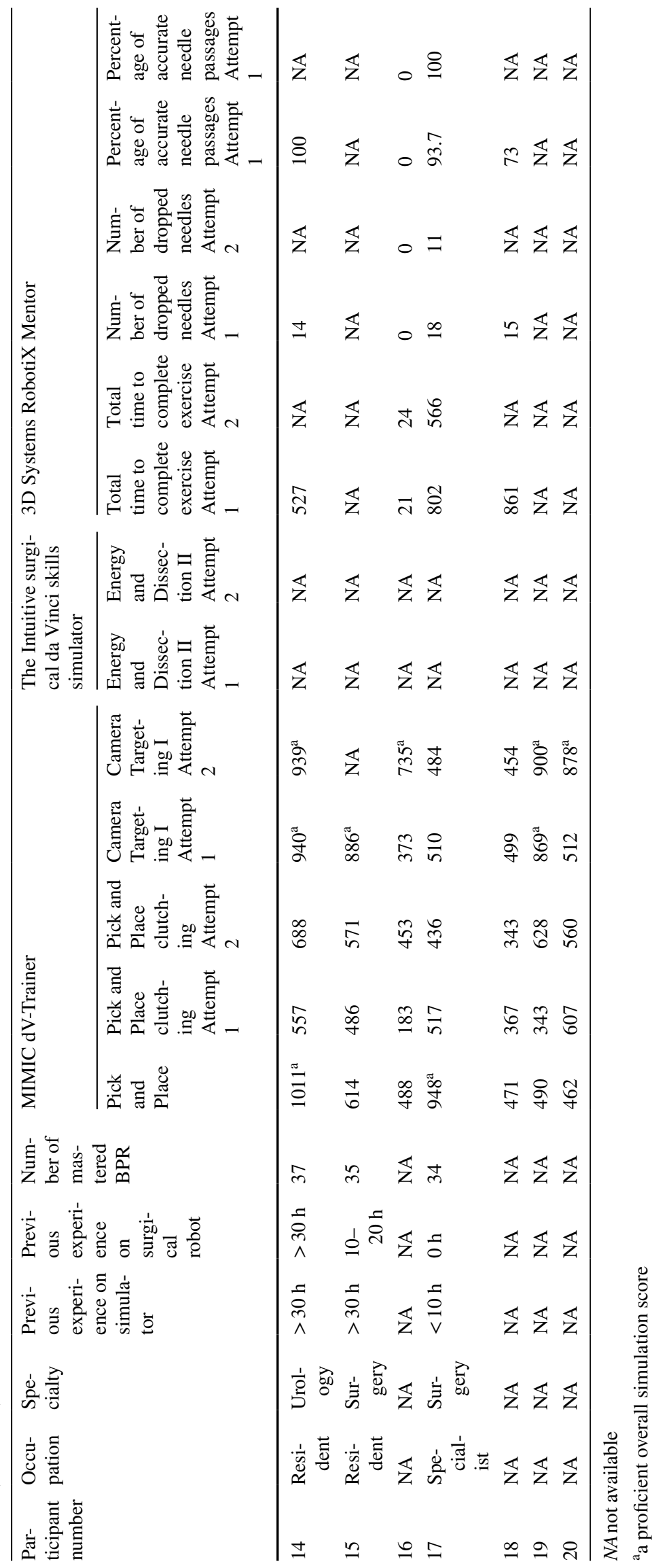




\section{References}

1. Brinkman W, de Angst I, Schreuder H, Schout B, Draaisma W, Verweij L et al (2017) Current training on the basics of robotic surgery in the Netherlands: time for a multidisciplinary approach? Surg Endosc Other Interv Tech 31(1):281-287

2. Dutch Health inspectorate (Inspectie voor de gezondheidszorg) (2010) Insufficient carefulness at the introduction of surgical robots (in Dutch: Onvoldoende zorgvuldigheid bij introductie van operatierobots). Igz, Utrecht

3. Khan R, Aydin A, Khan MS, Dasgupta P, Ahmed K (2015) Simulation-based training for prostate surgery. BJU Int 116(4):665674. https://doi.org/10.1111/bju.12721 (cited 2018 Mar 27)

4. Kruger J, Dunning D (1999) Unskilled and unaware of it: how difficulties in recognizing one's own incompetence lead to inflated self-assessments. J Pers Soc Psychol 77(6):1121-1134. https:// doi.org/10.1037/0022-3514.77.6.1121 (cited 2018 Mar 22)

5. Hadjipavlou M, Khan F, Fowler S, Joyce A, Keeley FX, Sriprasad S (2016) Partial vs radical nephrectomy for T1 renal tumours: an analysis from the British Association of Urological Surgeons Nephrectomy Audit. BJU Int 117(1):62-71. https://doi. org/10.1111/bju.13114 (cited 2017 Jan 7)

6. Jaeken M, Zech E, Brison C, Verhofstadt LL, Van Broeck N, Mikolajczak M (2017) Helpers' self-assessment biases before and after helping skills training. Front Psychol 8:1377. http://www. ncbi.nlm.nih.gov/pubmed/28861015. Accessed 22 Mar 2018

7. Porte PJ, Verweij LM, Bekkers RLM, Consten ECJ, Lichtenberg H, van der Poel HG, van Swol CFP, Wagner C (2017) Robotic surgery for medical specialists, basic proficiency requirements for the safe use of robotic surgery. NIVEL/EMGO+, Utrecht. https:// www.nivel.n1/sites/default/files/bestanden/Roboticsurgery_Medic alSpecialists.pdf. Accessed 22 Aug 2017
8. Smith R, Patel V, Satava R (2014) Fundamentals of robotic surgery: a course of basic robotic surgery skills based upon a 14-society consensus template of outcomes measures and curriculum development. Int J Med Robot Comput Assist Surg 10(3):379384. https://doi.org/10.1002/rcs.1559. (cited 2017 Aug 17)

9. Ahmed K, Khan R, Mottrie A, Lovegrove C, Abaza R, Ahlawat $R$ et al (2015) Development of a standardised training curriculum for robotic surgery: a consensus statement from an international multidisciplinary group of experts. BJU Int 116(1):93-101. http:// www.ncbi.nlm.nih.gov/pubmed/25359658. Accessed 25 Sep 2017

10. Wiener S, Haddock P, Shichman S, Dorin R (2015) Construction of a urologic robotic surgery training curriculum: how many simulator sessions are required for residents to achieve proficiency? J Endourol 29(11):1289-1293. http://www.ncbi.nlm.nih.gov/pubme d/26154108. Accessed 5 Dec 2017

11. Mimic Technologies Inc. (2016) dv Trainer by MIMIC, User Guide. Rev 3.5

12. Krueger J, Mueller RA (2002) Unskilled, unaware, or both? The better-than-average heuristic and statistical regression predict errors in estimates of own performance. J Pers Soc Psychol 82(2):180-188. http://www.ncbi.nlm.nih.gov/pubmed/11831408. Accessed 23 Mar 2018

13. Perrenot C, Perez M, Tran N, Jehl J-P, Felblinger J, Bresler $\mathrm{L}$ et al (2012) The virtual reality simulator $\mathrm{dV}$-Trainer ${ }^{\circledR}$ is a valid assessment tool for robotic surgical skills. Surg Endosc 26(9):2587-2593. https://doi.org/10.1007/s00464-012-2237-0 (cited 2017 Aug 9)

14. Schreuder HWR, Wolswijk R, Zweemer RP, Schijven MP, Verheijen RHM (2012) Training and learning robotic surgery, time for a more structured approach: a systematic review. BJOG 119(2):137149. https://doi.org/10.1111/j.1471-0528.2011.03139.x (cited 2017 Dec 5) 